\section{(O) OPEN ACCESS}

\title{
Contribution of health status and prevalent chronic disease to individual risk for workplace injury in the manufacturing environment
}

\author{
Jessica Kubo, ${ }^{1}$ Benjamin A Goldstein, ${ }^{1}$ Linda F Cantley, ${ }^{2}$ Baylah Tessier-Sherman, ${ }^{2}$ \\ Deron Galusha, ${ }^{2}$ Martin D Slade, ${ }^{2}$ Isabella M Chu, ${ }^{3}$ Mark R Cullen ${ }^{3}$
}

${ }^{1}$ Quantitative Sciences Unit, Stanford University School of Medicine, Stanford, California, USA

${ }^{2}$ Yale Occupational \& Environmental Medicine, Yale School of Medicine, New Haven, Connecticut, USA ${ }^{3}$ General Medical Disciplines, Stanford University School of Medicine, Stanford, California, USA

\section{Correspondence to} Dr Mark Cullen, General Medical Disciplines, Stanford University School of Medicine, 1265 Welch Road, MSOB X338, Stanford, CA 94305-

5411, USA; mrcullen@ stanford.edu

Received 7 June 2013 Revised 6 September 2013 Accepted 13 September 2013 Published Online First 16 October 2013

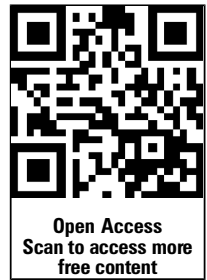

\section{SLinked}

- http://dx.doi.org/10.1136/ oemed-2013-101875

To cite: Kubo J Goldstein BA, Cantley LF, et al. Occup Environ Med 2014;71:159-166.

\section{ABSTRACT}

Objectives An 'information gap' has been identified regarding the effects of chronic disease on occupational injury risk. We investigated the association of ischaemic heart disease, hypertension, diabetes, depression and asthma with acute occupational injury in a cohort of manufacturing workers from 1 January 1997 through 31 December 2007.

Methods We used administrative data on real-time injury, medical claims, workplace characteristics and demographics to examine this association. We employed a piecewise exponential model within an Andersen-Gill framework with a frailty term at the employee level to account for inclusion of multiple injuries for each employee, random effects at the employee level due to correlation among jobs held by an employee, and experience on the job as a covariate.

Results One-third of employees had at least one of the diseases during the study period. After adjusting for potential confounders, presence of these diseases was associated with increased hazard of injury: heart disease (HR 1.23, 95\% Cl 1.11 to 1.36), diabetes (HR 1.17, $95 \% \mathrm{Cl} 1.08$ to 1.27 ), depression (HR $1.25,95 \% \mathrm{Cl}$ 1.12 to 1.38 ) and asthma (HR $1.14,95 \% \mathrm{Cl} 1.02$ to 1.287). Hypertension was not significantly associated with hazard of injury. Associations of chronic disease with injury risk were less evident for more serious reportable injuries; only depression and a summary health metric derived from claims remained significantly positive in this subset.

Conclusions Our results suggest that chronic heart disease, diabetes and depression confer an increased risk for acute occupational injury.

\section{INTRODUCTION}

Despite evidence that the workforce in developed countries is aging, and includes increasing numbers of workers with established chronic health risk factors and conditions, ${ }^{1}$ there is scant literature on the contribution of health to risk for occupational injury. As succinctly framed in the concluding paragraph of a 2008 systematic review of the subject, the information gap is both surprising and urgent to fill.'2

There are some relevant studies. Starting with disease risk factors, our group and others have shown that obesity is an independent risk factor ${ }^{3} 4$ with some suggestion of a dose-response relationship, but whether this increased risk is due to obesity per se or to obesity-related diseases, such as

\section{What this paper adds}

- Despite an aging population, there is scant literature on the effects of chronic disease on occupational injury risk.

- Some studies have shown higher risk of injury for those with depression, obesity, diabetes and asthma.

- We investigated the association of ischaemic heart disease, hypertension, diabetes, depression, asthma and acute occupational injury in a cohort of manufacturing workers for a 10-year period between 1997 and 2007.

- After adjusting for potential confounders, presence of these diseases was significantly associated with increased hazard of injury: heart disease (HR 1.23), diabetes (HR 1.17), depression (HR 1.25) and asthma (HR 1.14).

- Our results suggest that chronic heart disease, diabetes and depression confer an increased risk for acute occupational injury. Employees may benefit from strategies to reduce chronic disease.

diabetes, depression, asthma or cardiovascular disease, is unknown. A single controlled fitness intervention trial at an aluminium plant in Australia ${ }^{5}$ showed short-term injury reduction associated with weight loss, suggesting the former. Tsai et $a l^{6}$ has suggested that smoking is associated with increased risk, however, they did not control for social and medical covariates.

Specifically among health disorders, depression is the best studied with some consistency that depressed workers have higher risk of injury. ${ }^{7} 8$ Depending on the population studied, relative risks of injury among those with depression range from just above 1 to slightly over $3 .^{910}$ All these studies relied on subject self-report of depression and other known risk factors for injury, including differences in physical hazards of the work itself, were inconsistently managed, leading Palmer et $a l^{2}$ in review to infer that there is likely a higher risk associated with depression, but that evidence remains inconclusive. A recent study from Korea ${ }^{11}$ supports that conclusion, demonstrating modest but nonsignificant excess risks for occupational injury among those reporting depression on surveys. 
Diabetes has been less well studied, but there is also some evidence suggesting that affected workers are at excess injury risk, with relative risks in the $1.3-1.4$ range. $^{2}$ Notably, in the National Health Interview Survey results reported from 19962005, covering almost 200000 adult Americans, the risk was not significantly distinguished from 1 overall, though subgroups of sicker patients with diabetes had elevated risk. ${ }^{12}$ In none of these studies could the potential negative bias introduced by differential job selection of those in poorer health be addressed.

Asthma, hay fever and the medications used to treat them have been the subject of several reported studies with mixed results. Sprince et $a l^{13}$ show an odds ratio of 1.6 for asthma for injury among farmers, with even a higher risk among those working with livestock, but studies of allergy more generally in farmers and industrial workers have been contradictory. ${ }^{14} 15$ The evidence for hypertension and cardiovascular disease is even more limited, with no single study of sufficient quality or size to lend guidance.

In an effort to address this gap in the scientific literature, all the more pressing as the workforce ages and suffers high rates of chronic diseases, ${ }^{1}$ we have exploited our rich data on almost 40000 manufacturing workers of Alcoa at a range of medium to heavy production facilities in 24 states between 1997 and 2007; we truncated follow-up at this juncture to avoid any specific effects of the recession which impacted the industry heavily beginning in 2008. In previous reports, we have assessed the roles of overtime, job demand, sex, work organisation and time on job, in addition to the study of obesity referenced above (Souza et al, unpublished data, 2013). ${ }^{4}{ }^{16-18}$ Using an Andersen-Gill (AG) model with a piecewise exponential baseline hazard, and employee-level frailty term, we explore here the possibility that one or more prevalent chronic diseases or overall health status measured from health claims may explain some of the 'within-individual' risks previously modelled using a random frailty term. ${ }^{192021}$ Unlike previous studies, the use of exclusive and complete administrative health, injury and covariate data on the workers, and extensive knowledge about the jobs and their intrinsic risks, allows us to circumvent many of the limitations of the studies summarised above.

\section{METHODS}

\section{Study population}

The study population includes hourly-blue collar- manufacturing workers of a global aluminium company at 195 locations within the USA that were actively employed during the study period from 1 January 1997 through 31 December 2007. Data were obtained from a variety of sources including the employer's human resources databases, medical insurance claims data capturing each personal medical service, procedure, test or treatment provided and physician diagnosis for same, and a real-time incident management system established in 1989 in which details of every near-miss, first aid, or OSHA-recordable injury or incident are recorded within $48 \mathrm{~h}$ of occurrence. These sources are described in greater detail in previous publications. $^{17} 22{ }^{23}$ None of the data included are obtained from self-report.

As time to injury and experience on the job were of interest, only jobs that began after 1 January 1997 (incident jobs) were included in the cohort. For a given job to be included in the analysis, the employee needed to be eligible for company insurance during the duration of the job. Over $95 \%$ of the employees did, in fact, use the company plan except at three locations where a health maintenance organisation was heavily subscribed, so those plants were excluded. If, for a given job, the employee was missing only 1 year of health insurance data, the last observation carried forward was used to impute the missing year of data.

\section{Primary outcome}

The primary outcome is the time in months from the start of a particular job to any acute injury on that job. All occupational injuries, including first aid only and Occupational Safety and Health Administration (OSHA)-reportable injuries, are recorded in the realtime incident management system soon after they occur. Acute injuries include events, such as chemical/thermal burns, bruises, cuts/abrasions, fractures, instantaneous musculoskeletal injuries, and other incidents of sudden onset. Chronic conditions or events that are cumulative in nature, those classified as 'near-misses', or not directly related to work, do not meet the criteria for acute injury.

Employees who were not injured during the study period were censored at the first occurrence of: job change (defined as a significant change in job title), death, change to non-active status, or the end of the study period on 31 December 2007. To be included as distinct outcomes, injuries had to occur at least 1 day apart.

\section{Primary exposure}

The primary 'exposures' of interest were the presence of one of five disease states. Disease states were defined using medical claims data during the study period. We required one inpatient visit or two outpatient visits in the same calendar year of disease incidence; the disease was presumed to be present in every subsequent year as well. Asthma was defined using ICD9 codes of 493.XX and 496.XX; hypertension using 401.XX-404.XX; heart disease using 410.XX-414.XX; depression using 296.XX, 309.XX, and 311.XX; and diabetes using 250.XX.

\section{Secondary exposure}

Risk score measures were calculated for each year based on medical claims data and provide a measure of general health. Scores are based on an algorithm provided by Verisk for prediction of subsequent health claims based on a previous year in commercially insured populations. ${ }^{24}$ The risk score is a general metric for prediction of medical spending in the next year relative to the average employee at the company, and has been demonstrated by us and others to be a strongly associated, monotonically increasing predictor of absenteeism, disability and mortality (unpublished data). We incorporated risk score by year, aligning the previous year's risk score to the calendar year, and categorised scores into deciles in each year.

\section{Other covariates}

Calendar year, age at start of job, race, sex, whether the job was the first job at the company for the employee, and several plant-level characteristics including: business type, smelter plant type, and union status of the plant were all considered as potential confounders of the relationship between disease states and acute injury. Further, as the hazard of injury decreases after 1 year on the job, ${ }^{19}$ we adjusted for more than 1 year of experience as a potential confounder.

\section{Statistical analysis}

To compare employees with chronic conditions to those without, we used $\chi^{2}$ tests of association for categorical variables, and $t$ tests for continuous variables. All comparisons are to the group that did not have the disease in question during the study period (eg, for the heart disease column, the comparison is with those who did not have heart disease during the study period). 


\section{Models}

Survival methods were used to estimate relative rates of injury. Several complicating factors make the more typical Cox proportional hazards $(\mathrm{PH})$ model inappropriate. First, we have recurrent events because we included all injuries for a given person-job. Second, each person was allowed to have multiple jobs, meaning that we potentially have correlation among observations. Finally, based on previous work, ${ }^{19}$ we included an indicator for employee experience (12 months on that job) as a covariate. Such a variable is collinear with time, and cannot be included in a Cox PH model.

To address these issues, we used an AG model, which is an extension of Cox PH models. AG models allow for inclusion of multiple events per person (complication 1). ${ }^{25}$ For each model, we included a frailty term per individual which addresses correlation among jobs for the same employee (complication 2). ${ }^{20}{ }^{21}$ Finally, we employed a two-piece exponential hazard with a change of hazard at 12 months (complication 3). Two-piece exponential models are a special case of the Cox $\mathrm{PH}$ model; our model assumes a constant baseline hazard from 0-12 months on the job, and a separate constant baseline hazard from 12 months onward. ${ }^{19} 26$ Therefore, the final model was an AG model with a piecewise exponential baseline hazard, including a frailty term at the employee level. Calendar year and presence of disease in a year were incorporated in models as time-varying variables. Having more than 1 year of experience was incorporated as a time-varying variable by month.

We fit a series of models; the first (base model) adjusted for calendar year, 1 year of experience on the job, ethnicity, sex, whether the job was the employee's first at the company, the employee's age at the start of the job and whether the plant was a smelter, part of the union, or an original Alcoa business. In the next set of models, we examined the effect of the five diseases separately; here, each disease was included in a separate model. As disease state varied for a given employee by calendar year, these variables are incorporated as time-varying variables. A secondary analysis includes time-varying risk score, but none of the disease-status variables.

\section{Handling of missing data}

We excluded 150 employees from the analysis for the following reasons; sex could not be determined for 48 employees and ethnicity could not be determined for 122 employees. We performed a complete case analysis using all employees who were not missing any variables.

\section{Sensitivity analyses}

We performed a series of sensitivity analyses. First we restricted the outcome to injuries reportable to OSHA (more serious non-first-aid injuries). We also removed the job experience variable from the model, allowing us to fit a more traditional Cox $\mathrm{PH}$ model in the AG framework. A further sensitivity analysis restricted disease status to the year of incident disease diagnosis, defined as the year of the first inpatient claim or second of two outpatient claims. In these analyses, person-jobs are excluded if the start of the job occurred before the first diagnoses of a given disease. The final sensitivity analysis considered indicators for the five disease states in the same model to examine each disease of interest adjusted for the presence of the others.

\section{RESULTS}

Table 1 describes the entire cohort, which is comprised of 37900 distinct employees performing 83435 jobs at 195
Table 1 Characteristics of the cohort of hourly manufacturing workers from 1997 through 2007

\begin{tabular}{|c|c|c|}
\hline Characteristics & $\begin{array}{l}\text { Frequencyl } \\
\text { count }\end{array}$ & $\begin{array}{l}\text { Percent/mean (SD) } \\
\text { median }\end{array}$ \\
\hline Total employees & 37900 & \\
\hline Total jobs & 83435 & \\
\hline Total locations & 195 & \\
\hline Total injuries & 17785 & \\
\hline \multicolumn{3}{|l|}{ Employee-level } \\
\hline \multicolumn{3}{|l|}{ Sex } \\
\hline Male & 30245 & 79.80 \\
\hline Female & 7655 & 20.20 \\
\hline \multicolumn{3}{|l|}{ Ethnicity/race } \\
\hline American-Indian & 269 & 0.71 \\
\hline Asian/Pacific Islander & 631 & 1.66 \\
\hline Black/African-American & 5658 & 14.93 \\
\hline Hispanic/Latino & 3098 & 8.17 \\
\hline Caucasian & 28102 & 74.15 \\
\hline Other/multiple & 142 & 0.38 \\
\hline \multicolumn{3}{|l|}{ Job level } \\
\hline Age at start of job & & 41.21 (10.69) 41.38 \\
\hline Tenure at start of job & & $10.73(10.68) 6.47$ \\
\hline Length of job & & $1.88(1.92) 1.22$ \\
\hline \multicolumn{3}{|l|}{ Location level } \\
\hline Original plant & 46 & 23.59 \\
\hline Union plant & 10 & 5.13 \\
\hline Smelter plant & 9 & 4.62 \\
\hline \multicolumn{3}{|l|}{ Injury level } \\
\hline \multicolumn{3}{|l|}{ Severity } \\
\hline First aid (non-reportable) & 13078 & 73.53 \\
\hline Medical treatment & 2425 & 13.64 \\
\hline Restricted work & 2021 & 11.36 \\
\hline Lost work day & 261 & 1.47 \\
\hline \multicolumn{3}{|l|}{ Injury type } \\
\hline Abrasion/scratch & 1497 & 8.42 \\
\hline Burn (chemical/thermal) & 2371 & 13.33 \\
\hline Contusion/bruise & 3999 & 22.49 \\
\hline Foreign body & 1250 & 7.03 \\
\hline Laceration/cut & 3076 & 17.30 \\
\hline $\begin{array}{l}\text { Instantaneous sprain/ } \\
\text { strain }\end{array}$ & 3515 & 19.76 \\
\hline Other & 2077 & 11.68 \\
\hline
\end{tabular}

locations in the USA during the observation period. The cohort is largely male $(79.8 \%)$ and Caucasian $(74.2 \%)$. On average, employees were 41.2 years old when starting a new job, and had been at the company for 10.7 years. Jobs lasted nearly 2 years on average.

Table 2 presents descriptive statistics for employees who had any of the five diseases during the study period, and those who specifically had heart disease, hypertension, diabetes, depression, or asthma during the study period (non-mutually exclusive). For all diseases except depression, employees who had a disease were older and had a longer tenure at the company than those who did not. For all diseases, job length was significantly longer for those with a disease than for those without the disease. A higher percentage of women had depression and asthma during the study period. For all other diseases, the percentage of women who had the disease was lower. While severity of injury is not associated with most diseases, those with heart disease have a higher percentage of lost work days due to injuries than those without heart disease. 
Table 2 Characteristics of employees who had any of the diseases of interest at any point during the study period

\begin{tabular}{|c|c|c|c|c|c|}
\hline Characteristics & Heart disease & Hypertension & Diabetes & Depression & Asthma \\
\hline \multicolumn{6}{|l|}{ Count (\%) with each disease } \\
\hline Total employees (employee had disease ever) & $1544(4.07)$ & $6715(17.72)$ & $2373(6.26)$ & $1215(3.21)$ & $1127(2.97)$ \\
\hline Total jobs (employee had disease on that job) & $3701(4.44)$ & $16223(19.44)$ & $5554(6.66)$ & $3343(4.01)$ & $2871(3.44)$ \\
\hline Total injuries (employee had disease at time of injury) & $695(3.91)$ & $2757(15.50)$ & $1094(6.15)$ & $642(3.61)$ & $537(3.02)$ \\
\hline \multicolumn{6}{|l|}{ Employee level (count (\%)) } \\
\hline Sex & $\mathrm{p}<0.001$ & $p<0.001$ & $p<0.001$ & $p<0.001$ & $p<0.001$ \\
\hline Male & $1414(91.58)$ & $5524(82.26)$ & $2005(84.49)$ & $846(69.63)$ & $834(74.00)$ \\
\hline Female & $130(8.42)$ & $1191(17.74)$ & $368(15.51)$ & $369(30.37)$ & $293(26.00)$ \\
\hline Ethnicity/race & $\mathrm{p}<0.001$ & $p<0.001$ & $p<0.001$ & $\mathrm{p}<0.001$ & $\mathrm{p}<0.001$ \\
\hline American-Indian & $11(0.71)$ & $32(0.48)$ & $12(0.97)$ & $8(0.66)$ & $6(0.53)$ \\
\hline Asian/Pacific Islander & $8(0.52)$ & $67(1.00)$ & $29(1.22)$ & $1(0.08)$ & $7(0.62)$ \\
\hline Black/African-American & $156(10.10)$ & $1426(21.24)$ & $505(21.28)$ & $107(8.81)$ & 147 (13.04) \\
\hline Hispanic/Latino & $59(3.82)$ & $283(4.21)$ & $241(10.16)$ & $50(4.12)$ & $72(6.39)$ \\
\hline Caucasian & $1308(84.72)$ & 4887 (72.78) & $1564(65.91)$ & $1045(86.01)$ & $891(79.06)$ \\
\hline Other/multiple & $2(0.13)$ & $20(0.30)$ & $11(0.46)$ & $4(0.33)$ & $4(0.36)$ \\
\hline \multicolumn{6}{|l|}{ Job level (mean, SD) } \\
\hline Age at start of job & $\begin{array}{l}52.36^{* * *} \\
6.46\end{array}$ & $\begin{array}{l}48.32^{* * *} \\
8.74\end{array}$ & $\begin{array}{l}49.45^{* * *} \\
8.60\end{array}$ & $\begin{array}{l}41.18 \\
9.51\end{array}$ & $\begin{array}{l}44.62^{* * *} \\
10.08\end{array}$ \\
\hline Tenure at start of job & $\begin{array}{l}20.20^{* * *} \\
11.10\end{array}$ & $\begin{array}{l}17.12^{* * *} \\
11.53\end{array}$ & $\begin{array}{l}18.38^{* * *} \\
11.89\end{array}$ & $\begin{array}{l}11.05 \\
9.91\end{array}$ & $\begin{array}{l}14.12^{* * *} \\
11.11\end{array}$ \\
\hline Length of job & $\begin{array}{l}2.45^{* * *} \\
2.29\end{array}$ & $\begin{array}{l}2.46^{* * *} \\
2.29\end{array}$ & $\begin{array}{l}2.47^{* * *} \\
2.29\end{array}$ & $\begin{array}{l}1.99^{* *} \\
2.13\end{array}$ & $\begin{array}{l}2.25^{* * *} \\
2.20\end{array}$ \\
\hline \multicolumn{6}{|l|}{ Location level (count (percent)) $†$} \\
\hline Original plant & $925^{* * *}(59.91)$ & $3396 * * *(50.57)$ & $1211^{* * *}(51.03)$ & $662^{* * *}(54.49)$ & $631^{* * *}(55.99)$ \\
\hline Union plant & $718^{* * *}(46.50)$ & $2564^{* * *}(38.18)$ & $949 * * *(39.99)$ & $478^{* * *}(39.34)$ & $441^{* * *}(39.13)$ \\
\hline Smelter plant & $561 * * *(36.33)$ & $2102^{* * *}(31.30)$ & $746^{* * *}(31.44)$ & $322^{* * *}(26.50)$ & $318^{* * *}(28.22)$ \\
\hline \multicolumn{6}{|l|}{ Injury level (count (percent)) } \\
\hline Severity & $p=0.013$ & $p=0.761$ & $p=0.004$ & $p=0.473$ & $p=0.426$ \\
\hline First aid (non-reportable) & $528(75.97)$ & $2048(74.28)$ & $836(76.42)$ & $487(75.86)$ & $396(73.74)$ \\
\hline Medical treatment & $85(12.23)$ & $364(13.20)$ & $156(14.26)$ & 75 (11.68) & $67(12.48)$ \\
\hline Restricted work & $64(9.21)$ & 303 (10.99) & $88(8.04)$ & $70(10.90)$ & $62(11.55)$ \\
\hline Lost work day & $18(2.59)$ & $42(1.52)$ & $14(1.28)$ & $10(1.56)$ & $12(2.23)$ \\
\hline Injury type & $p=0.019$ & $p=0.236$ & $p=0.145$ & $p=0.109$ & $p=0.380$ \\
\hline Abrasion/scratch & $77(11.08)$ & $245(8.89)$ & $102(9.32)$ & $64(9.97)$ & $43(8.01)$ \\
\hline Burn (chemical/thermal) & $70(10.07)$ & $340(12.33)$ & $138(12.61)$ & $84(13.08)$ & $68(12.66)$ \\
\hline Contusion/bruise & $148(21.29)$ & $623(22.60)$ & $265(24.22)$ & $151(23.52)$ & $127(23.65)$ \\
\hline Foreign body & $44(6.33)$ & $172(6.24)$ & $71(6.49)$ & $29(4.52)$ & $33(6.15)$ \\
\hline Laceration/cut & $119(17.12)$ & $483(17.52)$ & $203(18.56)$ & $100(15.58)$ & $78(14.53)$ \\
\hline Instantaneous sprain/strain & $155(22.30)$ & 573 (20.78) & $211(19.29)$ & $138(21.50)$ & $114(21.23)$ \\
\hline Other & $82(11.80)$ & $321(11.64)$ & $104(9.51)$ & $76(11.84)$ & $74(13.78)$ \\
\hline
\end{tabular}

Of the 17785 injuries that occurred during the study period, the majority were treated with first aid, that is, not reportable to OSHA. Overall, $27410(72.3 \%)$ employees did not experience an injury during the study period; of the 10490 employees who experienced an injury 6469 experienced only one injury and 4021 experienced multiple injuries (with a maximum of one employee who had 14 injuries). The most common injury types were contusions and bruises, instantaneous sprains and strains, and lacerations and cuts.
Figure 1 Prevalence of diseases of interest by calendar year.

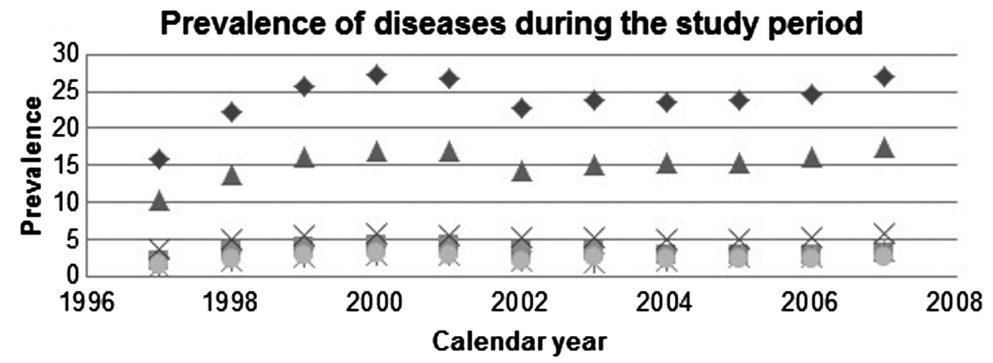


Table 3 HRs from Andersen-Gill models with piecewise exponential baseline hazard and employee-level frailty term of time-varying disease status

\begin{tabular}{|c|c|c|c|c|c|c|}
\hline Variable & Base model & Heart disease & Hypertension & Diabetes & Depress-ion & Asthma \\
\hline & HR $(95 \% \mathrm{Cl})^{\mathrm{p} \text { value }}$ & HR $(95 \% \mathrm{Cl})^{\mathrm{p} \text { value }}$ & $\mathrm{HR}(95 \% \mathrm{Cl})^{\mathrm{p} \text { value }}$ & $\mathrm{HR}(95 \% \mathrm{Cl})^{\mathrm{p} \text { value }}$ & HR $(95 \% \mathrm{Cl})^{\mathrm{p} \text { value }}$ & HR $(95 \% \mathrm{Cl})^{\mathrm{p} \text { value }}$ \\
\hline \multicolumn{7}{|l|}{ Comorbidities } \\
\hline \multicolumn{7}{|l|}{ Any comorbidity } \\
\hline Heart disease & & $1.23(1.11 \text { to } 1.36)^{* * *}$ & & & & \\
\hline Hypertension & & & $0.97(0.92$ to 1.02$)$ & & & \\
\hline Diabetes & & & & $1.17(1.08 \text { to } 1.27)^{* * *}$ & & \\
\hline Depression & & & & & $1.25(1.12 \text { to } 1.38)^{* * *}$ & \\
\hline Asthma & & & & & & $1.14(1.02 \text { to } 1.27)^{*}$ \\
\hline Calendar year (ref is 1997) & $* * *$ & $* * *$ & $* * *$ & $* * *$ & $* * *$ & $* * *$ \\
\hline 1998 & 0.94 (0.83 to 1.06$)$ & 0.93 (0.83 to 1.06$)$ & 0.94 (0.83 to 1.06$)$ & 0.93 (0.83 to 1.06$)$ & $0.93(0.83$ to 1.05$)$ & 0.93 (0.83 to 1.06$)$ \\
\hline 1999 & 0.83 (0.74 to 0.94$)$ & 0.83 (0.74 to 0.94$)$ & 0.83 (0.74 to 0.94$)$ & 0.83 (0.74 to 0.94$)$ & $0.83(0.74$ to 0.94$)$ & 0.83 (0.74 to 0.94$)$ \\
\hline 2000 & 0.92 (0.81 to 1.04$)$ & 0.91 (0.81 to 1.03$)$ & 0.92 (0.81 to 1.04$)$ & 0.92 (0.81 to 1.03 ) & 0.91 (0.81 to 1.03$)$ & 0.92 (0.81 to 1.03$)$ \\
\hline 2001 & $0.49(0.43$ to 0.56$)$ & $0.49(0.43$ to 0.55$)$ & $0.49(0.43$ to 0.56$)$ & $0.49(0.43$ to 0.55$)$ & $0.49(0.43$ to 0.55$)$ & $0.49(0.43$ to 0.55$)$ \\
\hline 2002 & 0.52 (0.46 to 0.59$)$ & 0.52 (0.46 to 0.58$)$ & 0.52 (0.46 to 0.59$)$ & 0.52 (0.46 to 0.59$)$ & 0.52 (0.46 to 0.58$)$ & 0.52 (0.46 to 0.59$)$ \\
\hline 2003 & $0.48(0.43$ to 0.54$)$ & $0.48(0.42$ to 0.54$)$ & $0.48(0.43$ to 0.55$)$ & $0.48(0.42$ to 0.54$)$ & $0.48(0.42$ to 0.54$)$ & $0.48(0.42$ to 0.54$)$ \\
\hline 2004 & 0.55 (0.48 to 0.62$)$ & 0.54 (0.48 to 0.62$)$ & 0.55 (0.49 to 0.62$)$ & 0.54 (0.48 to 0.62$)$ & $0.54(0.48$ to 0.61$)$ & 0.55 (0.48 to 0.62$)$ \\
\hline 2005 & $0.57(0.50$ to 0.64$)$ & $0.57(0.50$ to 0.64$)$ & $0.57(0.50$ to 0.64$)$ & 0.57 (0.50 to 0.64$)$ & $0.56(0.50$ to 0.64$)$ & $0.57(0.50$ to 0.64$)$ \\
\hline 2006 & $0.50(0.44$ to 0.56$)$ & $0.50(0.44$ to 0.56$)$ & $0.50(0.44$ to 0.56$)$ & $0.50(0.44$ to 0.56$)$ & $0.49(0.44$ to 0.56$)$ & $0.50(0.44$ to 0.56$)$ \\
\hline 2007 & $0.47(0.42$ to 0.53$)$ & $0.47(0.41$ to 0.53$)$ & $0.47(0.42$ to 0.53$)$ & 0.47 (0.41 to 0.53$)$ & $0.47(0.41$ to 0.53$)$ & $0.47(0.41$ to 0.53$)$ \\
\hline First 12 months on the job (inexperienced) & $1.22(1.17 \text { to } 1.26)^{* * *}$ & $1.22(1.18 \text { to } 1.26)^{* * *}$ & $1.21(1.17 \text { to } 1.26)^{* * *}$ & $1.22(1.18 \text { to } 1.26)^{* * *}$ & $1.22(1.18 \text { to } 1.26)^{* * *}$ & $1.22(1.18 \text { to } 1.26)^{* * *}$ \\
\hline Non-white ethnicity & $1.05(1.00 \text { to } 1.10)^{*}$ & $1.05(1.00 \text { to } 1.10)^{*}$ & 1.05 (1.00 to 1.10$)$ & 1.04 (0.99 to 1.09$)$ & $1.05(1.00 \text { to } 1.10)^{*}$ & $1.05(1.00 \text { to } 1.10)^{*}$ \\
\hline Male gender & $0.74(0.70 \text { to } 0.78)^{* * *}$ & $0.73(0.70 \text { to } 0.77)^{* * *}$ & $0.74(0.70 \text { to } 0.78)^{*}$ & $0.74(0.70 \text { to } 0.77)^{* * *}$ & $0.74(0.71 \text { to } 0.78)^{* * *}$ & $0.74(0.70 \text { to } 0.78)^{* * *}$ \\
\hline First job at company & $1.01(0.96$ to 1.06$)$ & $1.01(0.96$ to 1.06$)$ & $1.01(0.96$ to 1.06$)$ & $1.01(0.96$ to 1.06$)$ & $1.01(0.96$ to 1.06$)$ & $1.01(0.96$ to 1.06$)$ \\
\hline Age at start of job & $0.98(0.98 \text { to } 0.98)^{* * *}$ & $0.98(0.98 \text { to } 0.98)^{* * *}$ & $0.98(0.98 \text { to } 0.98)^{* * *}$ & $0.98(0.98 \text { to } 0.98)^{* * *}$ & $0.98(0.98 \text { to } 0.98)^{* * *}$ & $0.98(0.98 \text { to } 0.98)^{* * *}$ \\
\hline Smelter plant & $1.40(1.33 \text { to } 1.47)^{* * *}$ & $1.40(1.33 \text { to } 1.47)^{* * *}$ & $1.40(1.33 \text { to } 1.47)^{* * *}$ & $1.40(1.33 \text { to } 1.47)^{* * *}$ & $1.40(1.33 \text { to } 1.47)^{* * *}$ & $1.40(1.33 \text { to } 1.47)^{* * *}$ \\
\hline Union plant & $1.52(1.42 \text { to } 1.63)^{* * *}$ & $1.52(1.42 \text { to } 1.64)^{* * *}$ & $1.52(1.41 \text { to } 1.63)^{* * *}$ & $1.52(1.41 \text { to } 1.63)^{* * *}$ & $1.52(1.41 \text { to } 1.63)^{* * *}$ & $1.52(1.42 \text { to } 1.64)^{* * *}$ \\
\hline Original plant & $1.05(0.98$ to 1.12$)$ & 1.05 (0.98 to 1.12$)$ & $1.05(0.98$ to 1.12$)$ & $1.05(0.98$ to 1.12$)$ & 1.05 (0.98 to 1.12$)$ & 1.05 (0.98 to 1.12$)$ \\
\hline Frailty at employee level & $0.99(0.94$ to 1.05$)$ & $0.99(0.94$ to 1.05$)$ & $0.99(0.94$ to 1.05$)$ & $0.99(0.93$ to 1.05$)$ & $0.99(0.93$ to 1.05$)$ & $0.99(0.94$ to 1.05$)$ \\
\hline
\end{tabular}


Table 4 HRs from Andersen Gill models with piecewise exponential baseline hazard and employee-level frailty term of time-varying risk score

\begin{tabular}{|c|c|c|c|}
\hline Risk score & HR & $95 \% \mathrm{Cl}$ & $\mathrm{p}$ Value \\
\hline Risk score decile (\%) & & & $<0.001$ \\
\hline $0-10$ & Ref & & \\
\hline $10-20$ & 1.11 & 1.03 to 1.20 & \\
\hline $20-30$ & 1.07 & 0.99 to 1.15 & \\
\hline $30-40$ & 1.04 & 0.97 to 1.12 & \\
\hline $40-50$ & 1.13 & 1.05 to 1.22 & \\
\hline $50-60$ & 1.15 & 1.07 to 1.24 & \\
\hline $60-70$ & 1.20 & 1.11 to 1.30 & \\
\hline $70-80$ & 1.29 & 1.19 to 1.39 & \\
\hline $80-90$ & 1.25 & 1.15 to 1.35 & \\
\hline $90-100$ & 1.32 & 1.22 to 1.43 & \\
\hline
\end{tabular}

All models are adjusted for calendar year, experience on the job, gender, ethnicity, whether the job was the first at the company, employee's age at the start of the job, whether the plant was a smelter, whether the plant was a union plant, whether the plant was an original company plant, and a frailty term at the employee level.

Figure 1 depicts the prevalence of each disease by calendar year. All diseases exhibit an increase from 1997 through 2001, a slight drop in 2002, and a gradual increase from 2003 through 2007; these trends likely reflect the very low rate of turnover in an aging workforce, combined with a group of plant acquisitions which joined the cohort in 2001. One-third of employees were diagnosed with at least one of the five considered comorbid conditions at some point during the study period. The most common comorbidity was hypertension; presence of comorbidities in this cohort was similar to prevalence of comorbidities in the general population. ${ }^{27}$

In the first model, calendar year is significantly associated with acute injury $(\mathrm{p}<0.001)$ (table 3$)$. Compared to 1997, hazard of acute injury decreased significantly starting in 2001. Factors associated with increased hazard of acute injury include non-white race, female sex, younger age, working at a smelter plant, working at a union plant, and having less than

Table 5 Sensitivity analysis of reportable injuries only

\begin{tabular}{llll}
\hline Prevalent disease & HR & $95 \%$ Cl & p Value \\
\hline Heart disease & 1.02 & 0.86 to 1.20 & 0.843 \\
Hypertension & 0.92 & 0.84 to 1.00 & 0.058 \\
Diabetes & 1.00 & 0.87 to 1.14 & 0.968 \\
Depression & 1.18 & 0.99 to 1.40 & 0.065 \\
Asthma & 1.12 & 0.94 to 1.34 & 0.213 \\
Risk score & HR & $95 \%$ Cl & p Value \\
Risk score decile (\%) & & & $<0.001$ \\
$0-10$ & Ref & & \\
$10-20$ & 1.07 & 0.93 to 1.22 & \\
$20-30$ & 1.04 & 0.91 to 1.20 & \\
$30-40$ & 1.09 & 0.95 to 1.26 & \\
$40-50$ & 1.14 & 0.99 to 1.31 & \\
$50-60$ & 1.26 & 1.10 to 1.45 & \\
$60-70$ & 1.25 & 1.09 to 1.45 & \\
$70-80$ & 1.22 & 1.06 to 1.42 & \\
$80-90$ & 1.34 & 1.16 to 1.55 & \\
$90-100 \%$ & 1.37 & 1.18 to 1.58 & \\
\hline
\end{tabular}

1 year of experience on the job as previously shown in this workforce.

When modelled individually, presence of heart disease increased the hazard of injury by $23 \%$ (HR 1.23, 95\% CI 1.11 to $1.36, \mathrm{p}<0.001)$, presence of diabetes increased hazard of injury by $17 \%$ (HR $1.17,95 \%$ CI 1.08 to 1.27 , p $<0.001$ ), presence of depression increased the hazard of injury by $25 \%$ (HR $1.25,95 \%$ CI 1.12 to $1.38, \mathrm{p}<0.001)$, and presence of asthma increased the hazard of injury by 14\% (HR 1.14, 95\% CI 1.02 to $1.27, \mathrm{p}=0.021$ ). Hazard of injury did not differ significantly by presence of hypertension. Estimates for calendar year, age, sex, race, first job at company, smelter plant, union plant, and original plant did not change significantly when we adjusted for presence of comorbidities.

In secondary analyses, risk score decile was a significant predictor of acute injury $(p<0.001)$ (table 4$)$. Increasing by one decile carried an increase in hazard of 3\% (HR 1.03, 95\% CI 1.02 to $1.04, p<0.001)$. Compared with the lowest decile of risk score, those with the highest decile of risk score had an increased hazard of injury of 32\% (HR 1.32, 95\% CI 1.22 to 1.43).

In sensitivity analyses restricted to reportable injuries, only depression was borderline significantly associated with increased hazard of reportable injury $(\mathrm{p}=0.065)$; all the other HRs were close to 1 . Risk score decile, however, remained a consistent and significant predictor of reportable injury $(\mathrm{p}<0.001)$ (table 5). Increasing by one decile resulted in a $4 \%$ increase in hazard of reportable injury (HR $1.04 \mathrm{~m} \mathrm{95 \%} \mathrm{CI} 1.02$ to 1.05 , p <0.001).

A sensitivity analysis employing Cox $\mathrm{PH}$ models was also performed. In these models, the frailty term and experience on the job were removed. Results when all prevalent cases were included are unchanged from the main analysis (table 6, top panel). When only incident cases of disease (diagnosis after the start of a job) are included, results are virtually identical to the prevalence classification model (table 6, middle panel). A further sensitivity analysis incorporated the five indicators for presence of each disease state in the same model. Results and interpretation are unchanged using this model (table 6, bottom panel).

\section{DISCUSSION}

Our results, including the several sensitivity analyses, suggest that chronic heart and lung disease, diabetes and depression confer mild increased risk of acute occupational injury. Moreover, the analyses suggest that those with more health problems, or more severe ones as indicated by the general risk score, are at progressively higher risk for injuries of both first aid and more serious categories.

There are limitations to our observations that must be considered before interpreting these results. Most notably, although we control for general work environment, and are operating in a setting in which job comparability is known, we are unable to adjust for specific physical or psychosocial job demands. Although such data are available for a portion of our overall cohort $^{28}$ (Souza et al, unpublished data, 2013), they are unavailable for many of the locations, so we cannot be certain that there is not some confounding by actual job demand. That said, it is far more likely that sicker workers have either been assigned, or have chosen jobs with fewer physical demands; indeed, because of workplace policy, many with cardiovascular risks are excluded from hot jobs, and ongoing studies of dust suggest that those with diabetes, and ischaemic heart disease have less exposure to dust after diagnosis. This suggests that, if anything, this bias likely results in underestimation of the 
Table 6 Sensitivity analyses: The top panel shows the HRs using Cox proportional hazards models without frailty term, not adjusted for experience on the job. The bottom panel shows the HRs using incident rather than prevalent disease as the exposure

\begin{tabular}{lllr}
\hline Prevalent disease & HR & $\mathbf{9 5 \%} \mathbf{C l}$ & $\mathbf{p ~ V a l u e}$ \\
\hline Heart disease & 1.23 & 1.14 to 1.33 & $<0.001$ \\
Hypertension & 0.98 & 0.94 to 1.03 & 0.444 \\
Diabetes & 1.19 & 1.12 to 1.27 & $<.001$ \\
Depression & 1.31 & 1.21 to 1.41 & $<.001$ \\
Asthma & 1.14 & 1.04 to 1.24 & 0.003
\end{tabular}

Cox proportional hazards model. Results when all prevalent cases were included are unchanged from the main analysis

\begin{tabular}{lllr}
\hline Incident disease & HR & $\mathbf{9 5 \%} \mathbf{C l}$ & $\mathbf{p}$ Value \\
\hline Heart disease ( $n=80881$ jobs) & 1.34 & 1.17 to 1.52 & $<0.001$ \\
Hypertension ( $n=74613$ jobs) & 0.98 & 0.92 to 1.06 & 0.667 \\
Diabetes ( $n=79896$ jobs) & 1.18 & 1.06 to 1.31 & 0.003 \\
Depression ( $n=81$ 049 jobs) & 1.28 & 1.12 to 1.47 & $<0.001$ \\
Asthma ( $n=81$ 107 jobs) & 1.24 & 1.08 to 1.44 & 0.003 \\
\hline
\end{tabular}

Here any employee-job with a disease diagnosis before the start of the job was excluded from analysis separately for each disease. All models are adjusted for calendar year, experience on the job, gender, ethnicity, whether the job was the first at the company, employee's age at the start of the job, whether the plant was a smelter, whether the plant was a union plant, whether the plant was an original company plant, and a frailty term at the employee level

\begin{tabular}{|c|c|c|c|}
\hline Prevalent disease & HR & $95 \% \mathrm{Cl}$ & p Value \\
\hline Heart disease & 1.21 & 1.10 to 1.34 & $<0.001$ \\
\hline Hypertension & 0.95 & 0.90 to 1.01 & 0.077 \\
\hline Diabetes & 1.17 & 1.08 to 1.26 & $<0.001$ \\
\hline Depression & 1.25 & 1.13 to 1.38 & $<0.001$ \\
\hline Asthma & 1.12 & 1.01 to 1.26 & 0.040 \\
\hline
\end{tabular}

Model incorporating variables for presence of all five disease states in the same model.

All models are adjusted for calendar year, experience on the job, gender, ethnicity, whether the job was the first at the company, employee's age at the start of the job, whether the plant was a smelter, whether the plant was a union plant, whether the plant was an original company plant, and a frailty term at the employee level.

association, and may explain the weaker associations evident in the substudy of reportable injuries.

Our study may also suffer from data quality limitations. We have not individually normalised injury rates for actual hours worked per employee during each year; from a previous study, we know that large numbers of workers put in more than 40 or even $60 \mathrm{~h}$ a week. ${ }^{16}$ As with possible job differences, however, it is unlikely those with chronic disease worked, on average, longer than those without, so this bias too is far more likely to result in underestimate of the effect size. Although all our data are administrative, and maintained for business purposes, we cannot exclude the possibility that some of our results could spuriously emerge from incomplete reporting of both injuries and health; despite routine screening at work, we have evidence that men discovered at work to have hypertension or asthma, for example, often delay seeking medical attention ${ }^{22} 29$ rendering our classification flawed. We have no reason, however, to expect such behaviour would be differential with respect to $s u b$ sequent injury. Likewise, although previous work with these data has been reassuring, concerns about differential reporting of injuries, especially the more minor first aid injuries, could distort the association between injury and health; the direction of such a bias is ambiguous. Since we are relying on medical claims data, we do not have direct clinical information on disease severity-for example test results-other than by means of our summary risk scores, which integrate all the claims data into a single rating.

The possibility that some or all of our observed association between injury and chronic disease might be due to confounding by social status has not been directly excluded; indeed there is evidence of a relationship even with the hourly workers of higher rates of hypertension among those with lower ranking jobs. ${ }^{30}$ However, previous injury analyses have not shown any relationship between job 'grade' and injury risk once other risks, such as tenure, time on job, age and job demand are accounted for directly, reducing this concern. It must be kept in mind, too, that while the Alcoa workforce is very diverse ethnically and geographically, the effects of health on injury may be somehow unique to the aluminium industry, or to the unique safety culture of our study company; we note only the general consistency of the result with previous literature but also our hypothesis that sensory impairment, whether from disease or its treatment, might place an industrial worker at excess risk of acute injury. In this regard, it is somewhat reassuring that effects are seen for the symptomatic disorders, such as diabetes or asthma, but not hypertension.

Balancing these limitations against our study strengths-rich, prospectively obtained administrative data from multiple sites over many years-our results suggest that each of the major chronic conditions of a priori interest, save hypertension, increases risk for injury in the year of initial recognition (incidence) and thereafter. Moreover, there appears to be a monotonic rise in risk as one ascends in overall health-insurance risk category; the highest decile having about a one-third higher risk than the bottom decile, possibly an underestimate for the reasons highlighted above. While we could offer various diseasespecific hypotheses that might explain the observations, and cannot discount that such specific mechanisms may come to light with further study, the consistency in magnitude and direction across conditions suggest some more non-specific pathway or pathways are most likely at play including such factors as fatigue induced by disease or its treatments, common unifying 
risks such as obesity-already identified as a specific risk factor ${ }^{4} 31$ - and poor physical condition, distractions created by health concerns and needs for routine care and the like. Of these, fatigue, obesity and physical fitness would seem ample targets for initial intervention programmes to uncouple the health-injury relationship, even as further targeted research teasing out specific factors and causes proceed. Needless to say, as well, these findings demand confirmation in other workplaces where dangerous work is performed before more generalised interventions are developed and instituted among workforces with high rates of chronic disease. However, the trend towards workers retiring later in life, ${ }^{32}$ in part, a consequence of the demise of regular defined benefit pension plans supporting earlier retirements, render this line of research all the more urgent.

\section{CONCLUSIONS}

It appears likely that there is a real if small magnitude of association between symptomatic chronic disease and injury risk. While the observed effect is of modest size, development and testing of programmes designed to mitigate such risk offers yet another approach to the systematic control of workplace injury in manufacturing and possibly other sectors where serious injury risks remain intrinsic to work processes, and there are older workers with highly prevalent chronic diseases.

Contributors JK and MRC conceived the design of the study. BAG, LFC, BT-S and DG contributed subject matter expertise, aided in model design and data analysis. JK, MRC, BAG, LFC, BT-S and DG participated in literature review and the drafting and editing of the final manuscript.

Funding This research was funded by two grants from the National Institute on Aging (Disease, Disability and Death in an Aging Workforce, NIH/NIA, 1 R01 AG026291-06 and Alcoa Inc.). The funders had no role in the design of this study; collection, management, analysis and interpretation of the data, the conduct of this study, preparation, or approval of the manuscript. Alcoa reviewed the manuscript prior to publication.

Competing interests L Cantley, D Galusha, B Tessier-Sherman, IM Chu and MR Cullen receive a portion of their compensation at Yale and Stanford through a long-standing contractual agreement with Alcoa, Inc.

Ethics approval This study was approved by both Stanford and Yale University School of Medicine IRBs.

Provenance and peer review Not commissioned; externally peer reviewed.

Data sharing statement As an alternative to providing a deidentified dataset to the public domain, we allow access for the purpose of reanalyses or appropriate follow-on analyses by any qualified investigator willing to sign a contractual covenant with the host Institution limiting use of data to a specific agreed upon purpose, and observing the same restrictions as are limited in our contract with Alcoa, such as 60-day manuscript review for compliance purposes.

Open Access This is an Open Access article distributed in accordance with the Creative Commons Attribution Non Commercial (CC BY-NC 3.0) license, which permits others to distribute, remix, adapt, build upon this work non-commercially, and license their derivative works on different terms, provided the original work is properly cited and the use is non-commercial. See: http://creativecommons.org/ licenses/by-nc/3.0/

\section{REFERENCES}

1 Committee on the Health and Safety Needs of Older Workers-National Research Council. Health and safety needs of older workers. Washington, DC: The National Academies Press, 2004.

2 Palmer KT, Harris EC, Coggon D. Chronic health problems and risk of accidental injury in the workplace: a systematic literature review. Occup Environ Med 2008;65:757-64.

3 Tsai AG, Williamson DF, Glick HA. Direct medical cost of overweight and obesity in the USA: a quantitative systematic review. Obes Rev 2011;12:50-61.
4 Pollack KM, Cheskin LJ. Obesity and workplace traumatic injury: does the science support the link? Inj Prev 2007;13:297-302.

5 Morgan PJ, Collins CE, Plotnikoff RC, et al. The impact of a workplace-based weight loss program on work-related outcomes in overweight male shift workers. J Occup Environ Med 2012;54:122-7.

6 Tsai SP, Gilstrap EL, Cowles SR, et al. Personal and job characteristics of musculoskeletal injuries in an industrial population. J Occup Med 1992;34: 606-12.

7 Da Silva MC, Fassa AG, Kriebel D. Minor psychiatric disorders among Brazilian ragpickers: a cross-sectional study. Environ Health 2006;5.

8 Nakata A, Ikeda T, Takahashi M, et al. Impact of psychosocial job stress on non-fatal occupational injuries in small and medium sized manufacturing enterprises. Am J Ind Med 2006;49:658-69.

9 Zwerling CS, Sprince NL, Wallace RB, et al. Occupational injuries among agricultura workers 51 to 61 years old: a national study. J Agric Saf Health 1995;1:273-81.

10 Park H, Sprince NL, Lewis MQ, et al. Risk factors for work-related injury among male farmers in lowa: a prospective cohort study. J Occup Environ Med 2001:43:542-7.

11 Kim HC, Park SG, Min KB, et al. Depressive symptoms and self-reported occupational injury in small and medium-sized companies. Int Arch Occup Environ Health 2009:82:715-21.

12 Sprince NL, Pospisil S, Peek-Asa C, et al. Occupational injuries among workers with diabetes: the National Health Interview Survey, 1997-2005. J Occup Environ Med 2008;50:804-8

13 Sprince NL, Zwerling C, Lynch CF, et al. Risk factors for agricultural injury: a casecontrol analysis of lowa Farmers in the Agricultural Health Study. J Agric Saf Health 2003:9:5-18.

14 Bunn WB, Pikelny DB, Paralkar $S$, et al. The burden of allergies - and the capacity of medications to reduce this burden - in a heavy manufacturing environment. J Occup Environ Med 2003:45:941-55.

15 Xiang HY, Stallones L, Chiu YL. Nonfatal agricultural injuries among Colorado older male farmers. J Aging Health 1999;11:65-78.

16 Vegso S, Cantley L, Slade M, et al. Extended work hours and risk of acute occupational injury: a case-crossover study of workers in manufacturing. Am J Ind Med 2007;50:597-603.

17 Pollack KM, Agnew J, Slade MD, et al. Use of employer administrative Databases to identify systematic causes of injury in aluminum manufacturing. Am J Ind Med 2007:50:676-86

18 Taiwo OA, Cantley LF, Slade MD, et al. Sex differences in injury patterns among workers in heavy manufacturing. Am J Epidemiol 2009;169:161-6.

19 Kubo J, Cullen M, Cantley L, et al. Piecewise exponential models to assess the influence of job experience on the hazard of acute injury for hourly factory workers. BMC Med Res Methodol 2013;13:89.

20 McGilchrist CA, Aisbett CW. Regression with frailty in survival analysis. Biometrics 1991:47:461-6.

21 Aalen 00. Effects of frailty in survival analysis. Stat Methods Med Res 1994:3:227-43.

22 Tessier-Sherman B, Galusha D, Taiwo OA, et al. Further validation that claims data are a useful tool for epidemiologic research on hypertension. BMC Public Health 2013;13:51.

23 Cullen MR, Vegso S, Cantley $L$, et al. Use of medical insurance claims data for occupational health research. J Occup Environmen Med 2006;48:1054-61.

24 Bayer FJ, Galusha D, Slade M, et al. Process of care compliance is associated with reduced complications of diabetes. Am J Manag Care 2013 (In press).

25 Andersen PK, Gill RD. Cox regression-model for counting-processes-a large sample study. Ann Stat 1982:10:1100-20.

26 Friedman M. Piecewise exponential models for survival-data with covariates. Ann Stat 1982;10:101-13.

27 Key Statistics from NHANES National Health and Nutrition Examination Survey Data. Hyattsville, MD: Centers for Disease Control and Prevention (CDC). National Center for Health Statistics (NCHS), 2005-2006.

28 DeSanto lennaco J, Cullen MR, Cantley L, et al. Effects of externally rated job demand and control on depression diagnosis claims in an industrial cohort. Am J Epidemiol 2010;171:303-11.

29 Gulati M, Slade MD, Fiellin MG, et al. Healthcare for obstructive lung disease in an industrial spirometry surveillance program. J Occup Environ Med 2009:51:336-42.

30 Clougherty JE, Eisen EA, Slade MD, et al. Workplace status and risk of hypertension among hourly and salaried aluminum manufacturing employees. Soc Sci Med 2009; 68:304-13.

31 Poston WSC, Jitnarin N, Haddock CK, et al. Obesity and injury-related absenteeism in a population-based firefighter cohort. Obesity 2011;19:2076-81.

32 Voelker R. IOM: focus on care for aging population. JAMA 2008;299:2611-3. 